\title{
Unusual occurrence of abnormal skin pigmentation in blacktip reef sharks (Carcharhinus melanopterus)
}

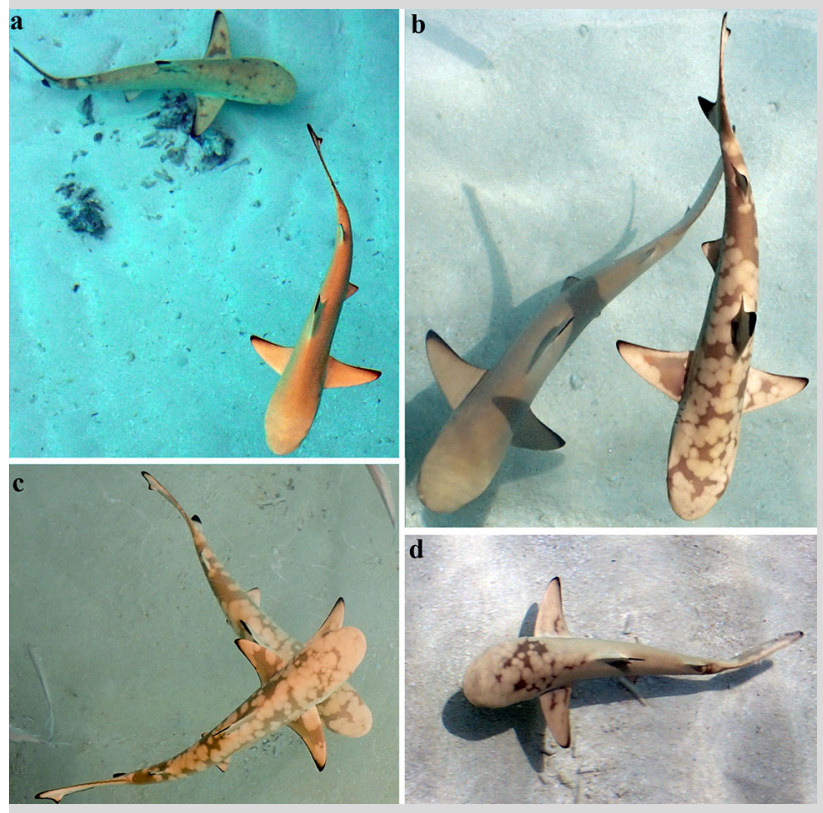

Fig. 1 Abnormal pigmentation in four Carcharhinus melanopterus individuals. a Partial body leucism and normal pigmentation. b Normal pigmentation and extreme case of abnormal pigmentation. $\mathbf{c}$ Two individuals with abnormal pigmentation. d Abnormal pigmentation between the head and trunk and on the fins
Total albinism has been reported in 26 shark species, including a single report in a blacktip reef shark (Carcharhinus melanopterus) from India (Manojkumar 2011). In Baa Atoll, Maldives, we identified eight young of the year (YOY; 40-60 cm) C. melanopterus with abnormal skin pigmentation that resembles leucism. Leucism, a genetic disorder reported in mammals, reptiles, amphibians, teleosts, and more recently elasmobranchs, is associated with abnormal skin pigmentation caused by a prenatal enzyme deficiency involved in the metabolism of melanin. This rare condition differs from true albinism as it is characterized by a reduction in melanin over the entire or part of the body, while affected animals have normal eye color (Lutz 2001).

In C. melanopterus normal body coloration is yellowbrown on their dorsal sides and white on their ventral side with a conspicuous black-tipped dorsal fin, and dark edging on pectoral fins and the upper lobe of the caudal fin. We observed irregularly shaped, dark color patches extending over their dorsal surface, pectoral fins, and caudal fins (Fig. 1). The eyes showed normal retinal pigmentation, and the blacktip and dark edging were still present on fins. Discoloration persisted for at least six months until present. These sharks occurred in an important nearshore habitat among a larger sample population $(n=25)$ of healthy, fully pigmented YOY. YOY individuals

have been utilizing this habitat for at least the previous six years; however, this is the first observation of abnormally pigmented individuals.

Atypical pigmentation in animals has been related to genetic alterations in melanin production, inbreeding within isolated populations, environmental stress associated with areas of high human activity, and exposure to elevated temperatures (Gervais et al. 2016). In the Maldives, this condition may be associated with heavy fishing pressure prior to 2010 , the current development boom, extensive land reclamation and burial of reefs to create artificial islands, or abnormally high sea water temperatures during the 2015-2016 El Niño. The abnormal pigmentation on sharks places them at greater risk of predation.

Acknowledgements This research was partially funded by the Greenville Zoo Conservation Fund.

Compliance with ethical standards

Conflict of interest On behalf of all authors, the corresponding author states that there is no conflict of interest.

\section{References}

Gervais C, Mourier J, Rummer J (2016) Developing in warm water: irregular colouration and patterns of a neonate elasmobranch. Mar Biodivers 4:743-744 Lutz CG (2001) Practical genetics for aquaculture. Blackwell, Oxford

Manojkumar PP (2011) First record of albinism in the blacktip reef shark Carcharhinus melanopterus from Malabar Coast. Mar Fish Inf Ser T \& E Ser 208:36

A. W. Bruckner (iD $(\bowtie) \cdot$ G. Coward

Coral Reef CPR, Sandy Spring, MD 20860, USA

e-mail: andywbruckner@gmail.com 